\title{
The Everyday Creativity of Authentic Classroom Assessments
}

\author{
M'Balia Thomas
}

\begin{abstract}
This paper examines the everyday creativity embedded within authentic classroom assessments. While not all authentic assessments are necessarily creative (i.e., novel, innovative, and contextually appropriate), I demonstrate everyday creativity in two authentic classroom assessments I have adopted in my TESOL courses. In revealing the everyday creativity of these tasks, and in light of their desired learning outcomes, I seek to demystify the role everyday creativity can play in student demonstrations of knowledge and skill.
\end{abstract}

\section{Background}

Educational scholarship often describes authentic classroom assessments as realistic, complex, and meaningful alternatives to traditional classroom assessments (Frey et al., 2012; Newmann et al., 1998; Wiggins, 1990). Additionally, authentic classroom assessments are heralded as providing feedback on teaching and student learning that is both "useful and meaningful" (Frey \& Schmitt, 2007, p. 402). Rarely mentioned, however, is that these assessments reflect and demand of learners (and of teachers) demonstrations of what the late educationalist, Ronald Carter (2004), describes as everyday creativity. Everyday creativity is a quotidian creativity expressed through the thought processes, rhetorical strategies, and rhythmic cadences students and teachers use to instruct, solve problems, and provide responses. Arguably, everyday creativity is a feature of many authentic classroom assessments, contributing to the realness, complexity, and meaningfulness associated with this category of assessment.

In this manuscript, I attempt to bridge the theory of everyday creativity with the practice of developing and implementing authentic classroom assessments. I do so to foreground the creativity inherent in these assessments and the affordances this creativity can impart upon teaching and student learning. I begin by introducing, contrasting, and interweaving the concept of everyday creativity as understood in my home fields of Applied Linguistics and Education. Next, I review the term authentic classroom assessments, and I highlight the everyday creativity potentially inherent within these assessments. By way of example, I present two authentic classroom assessments I use in my teaching-the first in an undergraduate TESOL methods course and the second in a graduate TESOL course. I reveal the creativity within and required by these authentic assessments, and I discuss their affordances to my teaching and to student learning. 


\section{Everyday Creativity}

While the field of Education embraces creativity as the ability or aptitude to produce contextually novel, innovative, or "appropriate" work (Beghetto, 2005, p. 255; Plucker et al., 2004), the field of Applied Linguistics emphasizes the notion of everyday creativity (Carter, 2004; Pennycook, 2007). This latter concept draws upon the educational notion of creativity while calling attention to the demotic, colloquial, everyday speech practices and rituals of language use in which creativity surfaces. Everyday creativity includes speech acts and language use whose novelty, innovation, and contextual appropriateness allow speech communities to address the diverse ways human beings tackle everyday tasks-including teaching and learning. Everyday creativity can also be observed in the most unexpected places, such as an ad encountered in a university bathroom stall in the United Kingdom (see Figure 1).

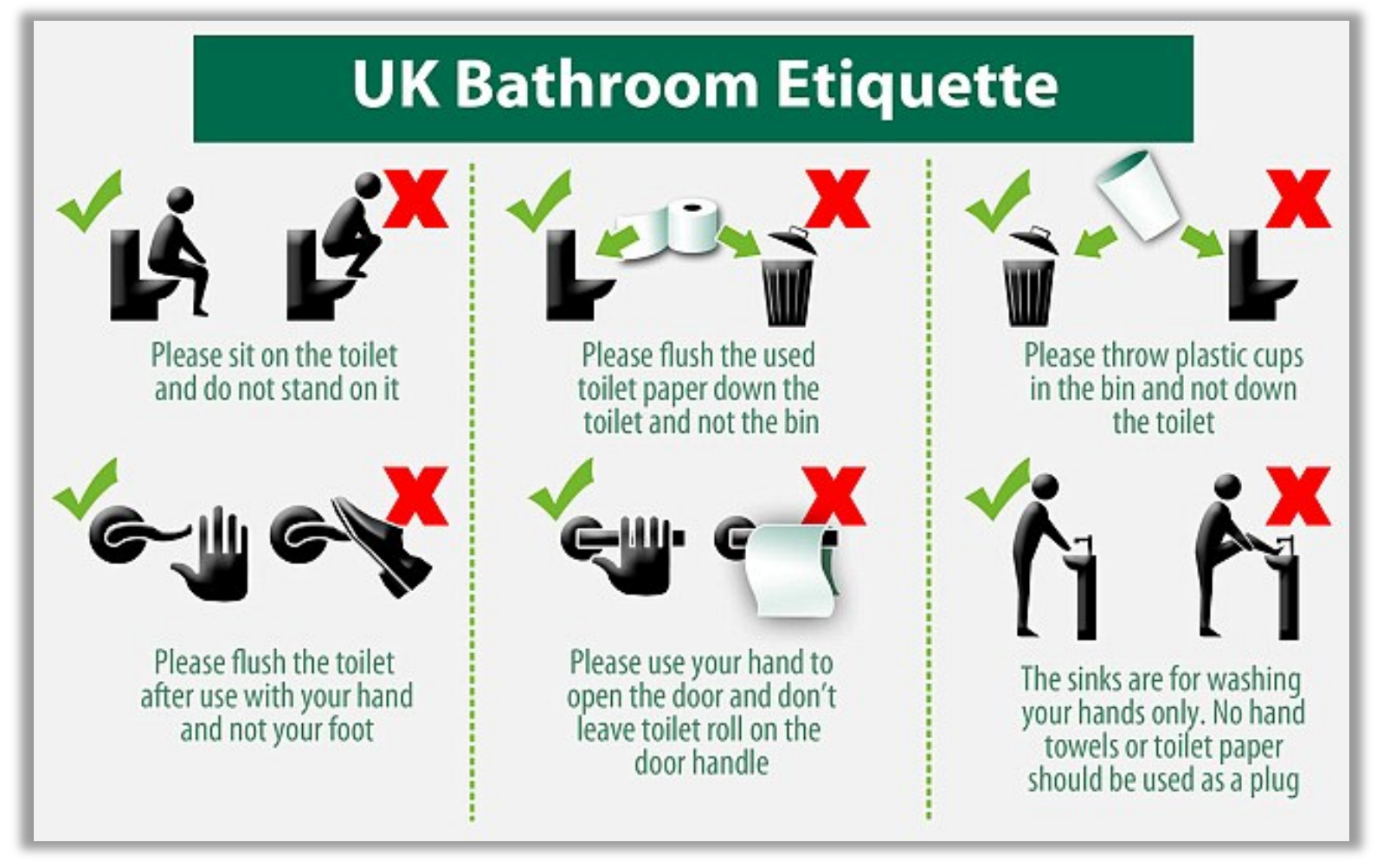

Fig: 1: UK bathroom etiquette

Everyday creativity is "both differently accented and socially constructed in different times and places" (Carter, 2004, p. 24); and therefore, it may be readily overlooked and even misrecognized-i.e., "strategically misconstrue[d]" (Warner, 2009, p. 21, referencing Bourdieu, 1977). In our present episteme, everyday creativity is attached to activity that is deemed "novel" - "new," "original," "made up" (Carter, 2004, pp. 26-27)—and that surfaces from a solitary human act and mind. While creativity can involve solitary action, it may incorporate as well "co-creation," "inventiveness," and "novelty and appropriacy" (Carter, 2004, pp. 27-28). Synonymous with appropriacy is usefulness, an important concept for "[t]hat which is novel but has no use, merit, or significance is simply novel, not creative" (Plucker \& Beghetto, 2004, p. 157). 
As a Critical Applied Linguist who is also a TESOL Teacher Educator, I am attuned to the everyday creativity present in teaching and learning. Everyday creativity surfaces in the classroom instruction teachers provide, the grading rubrics they design, and the didactic analogies and stories they producequite often on the spot and in inspired moments. Everyday creativity is expressed through the adoption of varied instructional modalities-Total Physical Response (TPR), song, dance, and other forms of embodied communication (see Catalano \& Leonard, 2016; Shin, 2017). This is creativity expressed not only through novelty or difference, but also through the demonstration of "repeated sameness" (Pennycook, 2007, p. 579). Such sameness includes the echo and repetition of wordplays, idioms, and puns, and the rhythm and systematicity of instructional delivery that work to promote meaning and uptake by students.

Everyday creativity also surfaces in the rhetorical styles adopted in academic speech and written texts that are designed to persuade, foster understanding, and entertain learners (Ardalan, 2015). Fahnestock (1999, 2003), for example, highlights the rhetorical strategies and figures of speech that mark the writing of science textbooks. She identifies the arguments and strategies of persuasion used by the texts' authors to build claims and describe scientific findings. These arguments and strategies include figures of speech such as the contradictory, yet proposition-advancing antithesis, the series generating incrementum, and the repeating forms of ploche and polyptoton (Fahnestock, 1999). Similarly, scholars in the fields of mathematics employ analogy pedagogically to make abstract and complex scientific concepts more readily understood (Glynn, 2007), and to enhance learning and retention (Garner, 2005).

Finally, everyday creativity manifests in my work as a Harry Potter Scholar. My research and teaching capitalize upon the generational knowledge preservice and inservice teachers have of the Harry Potter series. I use this already established knowledge to draw analogical comparisons between the linguistic and sociocultural practices of the fictional wizarding world into which the novels' muggle-born-and-raised characters are being socialized (e.g., Harry Potter and Hermione Granger), and similar processes of socialization faced by learners of English as an Additional Language (EALs) in real-world schools (Thomas, 2018a). With two graduate students, I have written about the personal and practical knowledge that wizarding teachers bring to student learning in everyday creative ways (Thomas et al., 2018). Through deeply personal and reflective writings, I have drawn upon the everyday creativity of intertextual and double-voiced speech (Bakhtin, 1984) to address themes of professional (re)socialization (Thomas, 2018b, 2018c, 2019).

Yet, while the everyday creativity of instruction, textbooks, and scholarship may be recognized willingly, its existence within the authentic classroom assessments of these instructional spaces has been overlooked. In the following sections, I build a case for the presence of everyday creativity in authentic classroom assessments. I begin by defining and unpacking this key term. 


\section{Authentic Classroom Assessments}

While a number of features are associated with authentic classroom assessments, I will highlight three. Firstly, authentic classroom assessments "mirro[r]...real-world tasks or expectations" (Frey et al., 2012, p. 1). Different from traditional assessments (which are often indirect measures of knowledge and skill), authentic assessments draw upon "performances and product requirements that are faithful to real-world demands, opportunities, and constraints" (Wiggins, 2006, n.p.). These assessments provide "useful" (Wiggins, 2006, n.p.), if not direct, feedback about the skills students are able to apply in context and the knowledge shown in the process. In addition, authentic assessments may incorporate real-world actors and possible actions (Newmann et al., 1998). Specific to the field of teacher education, authentic classroom assessments "simulate actual acts of teaching" such as teaching demonstrations and "examples of the work of teaching (videotapes of teaching, plans, and assessments of student learning....)" (Darling-Hammond \& Snyder, 2000, pp. 524, 527). These assessments provide students with insight into the work of the field.

Secondly, while real-worldness is a feature ascribed to authentic classroom assessments, Frey and colleagues (2012) posit that authentic tasks also "must mirror the complexity, collaboration, and high level thinking that is necessary in the most intellectual of professional problem-solving and decision-making" (p. 10). These tasks impose "more complex intellectual demands on students" and "elaborated communication" (Newmann et al., 2001, p. 10). For teacher educators, attending to complexity involves creating assessments that provide feedback on students' readiness to address the "integration of multiple kinds of knowledge and skill...used in practice" and to apply that knowledge in ways that take into account "the greater range of students from different backgrounds" and their "experiences and needs" (Darling-Hammond \& Snyder, 2000, p. 523).

Thirdly, authentic assessments are meaningful. Their meaningfulness derives from their direct (Wiggins, 1993), contextualized application of knowledge and skills, and the "value [they possess] beyond success in school" (Newmann et al., 1998, p. 19). Wiggins refers to this feature of authentic assessment as "transferability" - that is, "whether you can use your learning, [and] not merely whether you learned stuff" (2006, n.p.). Specific to the field of teacher education, meaningful assessments include "[case studies], exhibitions, portfolios, and problem-based inquiries (or action research)" (Darling-Hammond \& Snyder, 2000, p. 523). These assessments provided contextualized "opportunities for developing and examining teachers' thinking and actions in situations that are experience based and problem oriented and that include or simulate actual acts of teaching" (p. 524).

Thus, three characteristics—real-worldness, complexity, and meaningfulness-mark authentic classroom assessments. Next, I discuss the everyday creativity these three features offer to the authentic assessment of student knowledge and skills, and their significance for teacher education. 


\section{The Everyday Creativity of Authentic Classroom Assessments}

Authentic classroom assessments both reflect and require expressions of everyday creativity. The demonstration of everyday creativity in these assessments surfaces in their expectation of "original application of knowledge and skills, rather than just routine uses of facts and procedures" (Newmann et al., 2001, p. 14). Authentic classroom assessments oblige students to synthesize knowledge and "create...bridges from generalizations about practice to apparently idiosyncratic, contextualized instances of learning" (Darling-Hammond \& Snyder, 2000, p. 524). Furthermore, they encourage strategic and creative thinking that is reflective of real-world contexts, audiences, and situations. Ultimately, these creative demonstrations of knowledge can be presented through a variety of modalities and response types, although they are typically solicited through written or spoken rhetorical and argumentative strategies.

Additionally, the everyday creativity of authentic classroom assessments is reflected in the varied cognitive skills students need to complete these assessments. These skills include "conducting research; writing, revising and discussing papers; providing an engaging oral analysis of a recent political event; collaborating with others on a debate, etc." (Wiggins, 1990, p. 1). The everyday creativity of these actions emerges in the language skills students draw upon to dialogue with, double-voice, and intertextually reference authorized (scholarly) knowledge. This knowledge is shaped by, and sometimes in conflict with, expert-others where it is revoiced with a "sideward glance" (Bakhtin, 1984, p. 196) to the response anticipated by the instructor and the field of teaching and teacher education in general.

Finally, because authentic classroom assessments draw upon real-world and complex phenomenon, "there may be no right answer, and [a response] may not be easily scored" (Wiggins, 1998, n.p.). Thus, the everyday creativity of these assessments is demonstrated in the contextual appropriateness, meaningfulness, and usefulness of a given response. Furthermore, the flexibility required on the part of teachers to score these assessments may spark additional everyday creativity through the creation of innovative grading rubrics that appropriately and usefully offer guidance and feedback to learners.

While authentic classroom assessments may give rise to expressions of everyday creativity, such creativity can be cultivated. According to Beghetto (2005), creativity is fostered in authentic classroom assessments in two stages. The first, or divergent, stage is marked by the free-flowing generation of knowledge and ideas. This stage is represented by the act of brainstorming without concern for evaluation or merit (Beghetto, 2005). This stage elicits and injects a personal and practical kind of knowledge into a situated (or contextualized) problem or task. In the second, or convergent, stage, students must evaluate and select an idea that moves the project forward. In these instances, not only creativity — but also everyday creativity — can be expressed through the novel, appropriate, and useful knowledge and rhetorical strategies individuals take up to move projects through to completion. These include the ways individuals "use their evaluative thinking skills, check the appropriateness and social validity of their efforts, persevere in the face of difficulty, and follow through by completing their project and publishing their work" (p. 257). 
In my own teaching and assessment, I have sought to nurture everyday creativity though the authentic classroom assessments I have assigned to my students over the years. In the sections that follow, I describe two authentic classroom assessments I have adopted as end-of-unit summative assessments. The first, "The Supervisory Observation Report," features in an undergraduate TESOL methods course, while the second, "The Conference Poster Presentations," is used in a graduate curriculum and teaching course for inservice teachers and full-time doctoral students. For each assessment, I present a context for the assessment, I unpack the authentic aspects of the assessment, and I provide an overview of the everyday creativity these authentic assessments demand and afford learners in terms of demonstrating higher order thinking and knowledge production.

\section{The Supervisory Observation Report}

The Supervisory Observation Report is an authentic classroom assessment that I have used in my undergraduate course, "Instructional Approaches for ESOL Learners in the Middle / Secondary Classroom" (Thomas, n.d.a). Designed for middle and secondary preservice teachers in the content area-Social Studies and Government, English Language Arts, and Foreign Language Education-this required course has incorporated a number of authentic assessments over the years. I have had students write a professional teaching resume, create lesson plans, and then deliver a mini-teaching demonstration. While resumes are useful artifacts for students to create, they serve a purpose apart from the demonstration of student knowledge and experience in that they allow me to get to know my students beyond the surface level of race, gender, and program of study. Through the curriculum vitae of their young adult lives, I glean their lived experiences, talents, languages learned and spoken, range of employments, and places they have lived. In the same way, the lesson plans students create, while decontextualized and lacking in real-world meaningfulness, allow students to demonstrate and apply their knowledge in novel, inventive, and appropriate ways.

To create a contextualized and potentially meaningful authentic classroom assessment, I constructed the Supervisory Observation Report to challenge students to apply their TESOL knowledge to a pedagogical problem. To address the problem, students must draw upon their familiarity with the stages of second language acquisition, academic English proficiency, and language complexity at the word, sentence, and discourse levels. Students read, comprehend, analyze, and select contextually appropriate pedagogical suggestions, drawing from possible pedagogical actions outlined in the course readings. Lastly, students reveal their dispositional stance toward EALs through assessment of the context, challenges, and pedagogical recommendations provided to the teacher. Successful performance on this authentic assessment is marked not only by the contextual appropriateness of the recommended pedagogical strategies, but also by the rhetorical support that provides evidence of the socioemotional, cultural, and linguistic issues at stake in the teaching and learning context.

The teaching and learning context provided for this assessment is taken from a 12-minute fictionalized short story film entitled "Immersion" (Levien, 2009). Set in a multiracial and multilingual classroom setting with real-world actors (Newmann et al., 1998), the film introduces, "Moises," a fifth-grade EAL. 
While successful at decoding math word problems, Moises struggles to communicate his mathematics knowledge successfully in English. In addition to observing Moises' linguistic and subsequent socioemotional struggles, the audience witnesses the frustrated attempts of a second actor to address his language needs-Moises' classroom teacher, "Ms. Peterson."

\section{The Assessment}

The Supervisory Observation Report places students in the imaginary role of evaluating a teacher's pedagogical response to the limited English proficiency of an Emergent Bilingual and offering pedagogical feedback to improve this response. Students are given the prompt below to the assessment:

Ms. Peterson has asked you as the curriculum supervisor for the school to observe her classroom teaching and interaction with Moises. She has asked that you provide input on her pedagogical techniques and provide suggestions, recommendations, advice on pedagogical strategies that she should use to support and build Moises' Academic English Proficiency and prepare him for the upcoming standardized test. (Supervisory Observation Report)

The Supervisory Observation Report requires students to glean relevant details about the context of learning (the classroom situation, the learner, and the teacher) in order to suggest contextually appropriate courses of action to the fictional classroom teacher. The assessment is authentic in that it compels students to engage in simulated acts of teaching observation. In fact, students must watch the film several times, jotting down notes and attempting to weigh which elements of curriculum making present on screen might be relevant to determining future pedagogical actions. In this sense, this assessment "sample[s] the actual knowledge, skills, and dispositions desired of teachers as they are used in teaching and learning contexts" (Darling-Hammond \& Snyder, 2000, p. 527).

Finally, while this authentic assessment does not provide "direct interaction with students" (Darling-Hammond \& Snyder, 2000, p. 524), it does require students to engage with the complexity of teaching and learning in meaningful, contextualized, and useful ways. Students must work toward a goal they explicitly understand, even if they are unsure what the best method is to arrive at that goalto provide instructional supports for a limited English proficiency student that will increase their participation in class and on a standardized test. The assessment requires complex thinking as students strive to 1) assess Moises' level of English language proficiency, 2) determine the stated and inferred pedagogical constraints to increased language proficiency (from the perspectives of the teacher and the student), and 3) recommend the pedagogical actions to support increased proficiency based on best practices featured in our ESOL course reader. Finally, like the real-world, students must be able to justify their recommended courses of action by providing evidence from the learning context.

\section{The Everyday Creativity in this Authentic Assessment}

The Supervisory Observation Report requires the creative identification and application of "multiple sources of evidence...collected over time and in diverse contexts" (Darling-Hammond \& Snyder, 2000, p. 527). This evidence is provided over time and space through the fictionalized short film. The 
assessment requires students to attend closely to the people, things, and processes (Connelly \& Clandinin, 1988) present within the fictionalized classroom space. In their assessments, my students exhibit varying degrees of success in pointing out aspects of the situated context that are pedagogically relevant. For example, in his Supervisory Observation Report, "Cal" — a pseudonym, as are all student names presented in this paper-describes the pedagogical context of one of the opening classroom scenes as follows:

The student, Moises, is struggling to process new content in a language he does not understand. He is clearly bright and knows to look around for visual cues, but he runs into roadblocks with vocabulary such as Tier 2 words like "block." He is trying to process the auditory input of the language in addition to reading word problems. The events taking place in the learning environment include a lot of verbal instruction and very little emphasis on written and visual cues to accompany spoken word. Ms. Peterson doesn't appear to know how to most effectively ask questions to ELL's and repeats statements that are clearly not clicking, such as the scene where Moises answers the word problem. The urgency is not only set by his slowed rate of proficiency but the impending standardized testing to take place. (Cal, Supervisory Observation Report)

The report also challenges students to anticipate aspects of the teaching and learning environment-its structural, sociopolitical, environmental, temporal, interactional, and spatial contexts - that bear on their pedagogical recommendations. For example, although the film does not provide a calendar date, the mention of school-wide testing in this U.S.-based school suggests students are entering the spring standardized assessment period. Likewise, given a conversation held between the classroom teacher and a colleague, students discover that in this sociopolitical setting, teachers cannot translate content for students and students cannot use bilingual dictionaries. Despite these limitations, there are affordances. The classroom is designed for collaboration — students are seated side by side in pairs and Moises is shown speaking with various classmates, even if he struggles to fit in socially. The multiple and varied contextual details the film provides allows students to craft individual, novel, and appropriate pedagogical recommendations. It is with respect to such contextual elements that "Jo" offers the following pedagogical suggestion in their report:

It is clear that many students did not produce the same/correct answer for the math problem, so it would be beneficial to allow students to work together and orally discuss what steps they took to solve the math problem. This would allow Moises the opportunity to share his feedback without so much spotlight specifically on him, and giv[e] support and a safe space to discuss with his classmates. (Jo, Supervisory Observation Report)

The report further challenges students to think creatively about the utility of the people, objects, and processes present in the learning context. However, noticing and drawing conclusions about the curriculum-making elements present in the classroom are not intuitive processes for many preservice teachers. Over time, I have come to recognize that student success in this area is contingent on me as instructor explicitly guiding students in the ways of reading (seeing) a classroom as an experienced educator. This explicit instructional practice increases the possibilities that students will make connections between the TESOL pedagogy discussed in class and in our readings and the people, objects, and processes present in a classroom setting that make particular pedagogical actions possible (such as utilizing classmates as learning partners or even language brokers, or scanning the classroom for wall-based materials to use). It is possible to see such a connection arise for "Fran" who notes in their observation report: "I observed that there were posters and other visual aids in the classroom that Moises 
used during the class; however, it was not evident that Ms. Peterson suggested these visuals be used to help with classwork" (Fran, Supervisory Observation Report).

Moreover, the report calls upon students to take up the speech acts and discursive practices that are part of the written argumentations and oral deliberations of teaching, such as advocate, list, persuade, synthesize, and plan. These discourse strategies are part of students' everyday rhetorical repertoire and they can be drawn upon to communicate the professional knowledge, skills, and dispositions students possess as preservice teachers.

\section{The Conference Poster}

The Conference Poster is an authentic assessment I use in my course, "Language, Discourse, \& Ideology" (Thomas, n.d.b). This theory-driven graduate course explores the original writings and applied theories of Bourdieu, Foucault, and Bakhtin. Rather than submit lengthy term papers as summative assessments, students demonstrate their understanding and application of theory to practice through the creation of a series of Conference Posters. By the semester's end, students will have created three distinct posters reflecting their application of theoretical knowledge based on the work of the three theorists studied.

3

su

\section{Social Media Advocacy by Parents of Children With Disabilities}

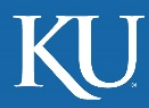

\section{"ADVOCATE LIKE A MOTHER"}

This image comes from @TheLuckyFew, which is an Instagram account ran by a heterosexual, married, White, middle-class, native English-speaking couple who live in Southern California
and have three adopted children, two of whom have disabilitics.

Families who are not White, middle-class, and native Englishspeakers may be further oppressed by the narratives (re)produced by families from privileged backgrounds. Although this mother provides one example of how a parent can engage in advocacy, not all parents will advocate in the sa
ways, especially if their capital does not align with White, middle-class, native English-speaking mothers.

MOTHERHOOD: RACE, CLASS, GENDER The "Advocate like a Mother" shirt perpetuates certain ideologies and displays privilege. The purchase (i.e., economic capital) and wearing of the shirr (1.e., cultural capital) link this (a) also have children with disabilities, (b) advocate similarly and (c) share similar values (Bourdieu, 1986).

In the caption, the mother describes the steps she has taken to advocate for her child. This suggests that she has the time, energy, support, knowledge, and familiarity to navigate educational hierarchies, which perpetuates White, middle-class, English-speaking, motherhood ideologies abo
their child with a disability (Ong-Dean, 2009).

\section{IDEOLOGIES ABOUT LANGUAGE, ETC}

Ideologies about languase surrounding "Advocate like a Mother" imply that mothers
serve as advocates and that there are specific ways to advocate.

Her habitus is conveyed through her language use and defines who she is as a language user (i.e., the types of social connections she may have and the language that intor actions; Weininger, 2005)
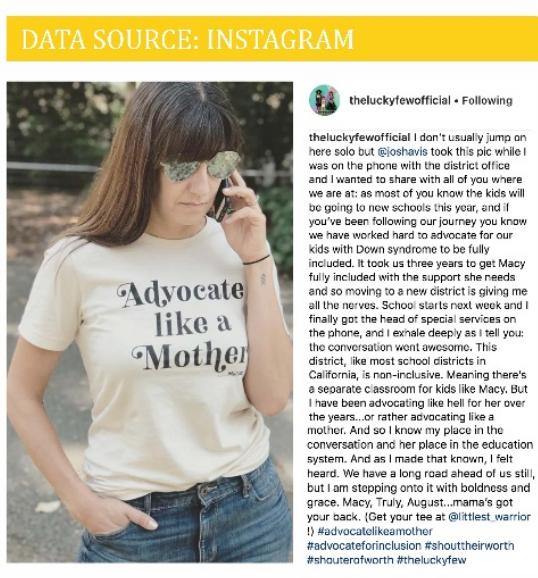

\section{WHAT'S IN A NAME: @THELUCKYFEW}

Names serve as a guide to identifying people, places, and things, but names can also invoke connotations and
or subject's name (Nilsen \& Nilsen, 2009).

The family who runs @TheLuckyFew account describe that they are lucky to have adopted their children, and are especially lucky to be parents of children with disabilities. They communicate this message to their socis media followers and perpetuate an ideology that parents who have children with disabilities are "strong" advocates and "lucky,"

However, @Theluckyfew also could imply that they are lucky because they are White, middle-class, native English-speakers and have power are from dominated backgrounds may be unfucky and unable.

\section{OPPOSITIONAL STRATEGY}

Social media photonarratives are an oppositional strategy. Mothers fram privileged backgrounds demonstrate logic that aligns with educational bureaucracies as they engage in
advocacy strategies (De Certeau, Jameson, \& Lovitt, 1980).

These ideologies are generated, consumed, and reified by White, middle-class, native English-speaking mothers of children with disabilities.

\section{FUTURE DIRECTIONS}

Qualitative analysis could include discourse analysis of the as well as visualanasis of the

Quantitative measures can provide frequencies of words and ideologies, as well as surveying parents about attitudes, perceptions, and beliefs on "advocacy" in special education

Findings would provide unique insight on parent advocacy as an act of privilege and domination. The current state of research in this area mistakenly generalizes the actions an behaviors of White, middle-class, native English-speaking mothers as actions and behaviors of $a / l$ parents.

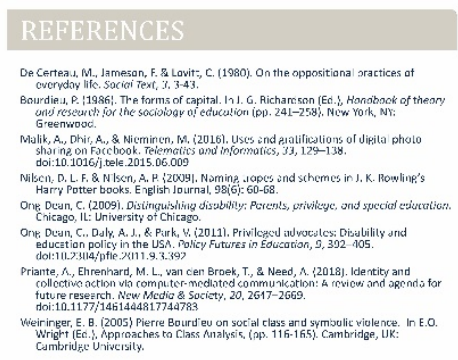

Fig. 2: Social media advocacy by parents of children with disabilities 
The Conference Poster allows students to address the real-world challenges of communicating a theoretical argument succinctly, analytically, and visually for their academic peers. It also prepares students for the oral and public aspects of defending novel ideas through their comprehensive exams and dissertations. Finally, this authentic classroom assessment supports my department's goals of fostering professionalization among our part-time EdD and full-time doctoral students.

\section{The Assessment}

The Conference Poster tasks students to find text or talk ("data") that can serve as a basis for a Bourdieuian, Foucauldian, or Bakhtinian argument and that can demystify ideologies present within the data. Each poster presents a context for the data and includes a statement of the problem. This problem is then theoretically unpacked, linguistically analyzed (or a proposed approached to analyzing the data is offered), and the material/symbolic effects or the oppositional practices reflected in the data are highlighted and discussed. Through this assessment, students reveal their understanding of theoretical concepts and their implications in real-world settings.

I designed the course so that students would have three weeks to select their data, discuss their data with classmates (and with me), outline a plan of execution, and create the poster. Pre-COVID, these final conference posters were displayed on the classroom wall and the first 30-45 minutes of class were spent perusing the array of posters while enjoying hot apple cider and snacks. A Q\&A session followed the public display of posters. During the Fall 2020 pandemic, the course was taught via Zoom, so conference posters were uploaded electronically to VoiceThread, a collaborative media space where participants can add public comments to video and text. Students were required to record a five-minute audio presentation to accompany their poster. The online presentations were set up like a virtual art gallery and students had a week to view and comment on their classmates' poster presentations. The comments and feedback where encouraging, generous, and instructive. Moreover, they resulted in dialogic engagement between students and their ideas, occasionally by students following up to feedback offered by their classmates.

\section{The Everyday Creativity in this Authentic Assessment}

As an "exhibition of performance" (Darling-Hammond \& Snyder, 2000, p. 529), the Conference Poster provides students an opportunity to present and defend their academic work in "novel and useful" ways (Plucker et al., 2004, p. 90). The assessment requires students to create "a product...that has meaning or value beyond success in school" (Wiggins, 2006, p. 51). Moreover, since the posters are displayed for public exhibition, the assessment allows for student performance that is "assessed in a context more like that encountered in real life" (Dez et al., 1992, pp. 38-39). Thus, meaningfulness and transferability of knowledge are important features of this authentic assessment.

Additionally, the course requirement to create three poster presentations is an exercise in repetitionthat is, sameness as difference, or rather, repetition as "recreative" (Pennycook, 2007, p. 584). For example, the creation of a conference poster challenges students to express their knowledge in same but different ways across multiple modalities—written word, visual representation, and spoken word. 
In addition, students are required to take up this assessment several times. One can observe the ways students take the same poster structure and rekey (Goffman, 1974) it in novel, individual, and expressive ways across three different theorists. The assessments repeat, parallel, and build upon previous posters, but also deviate from one another in significant ways. Finally, it is possible to see the evolution of student argumentation and presentation skills over multiple iterations.

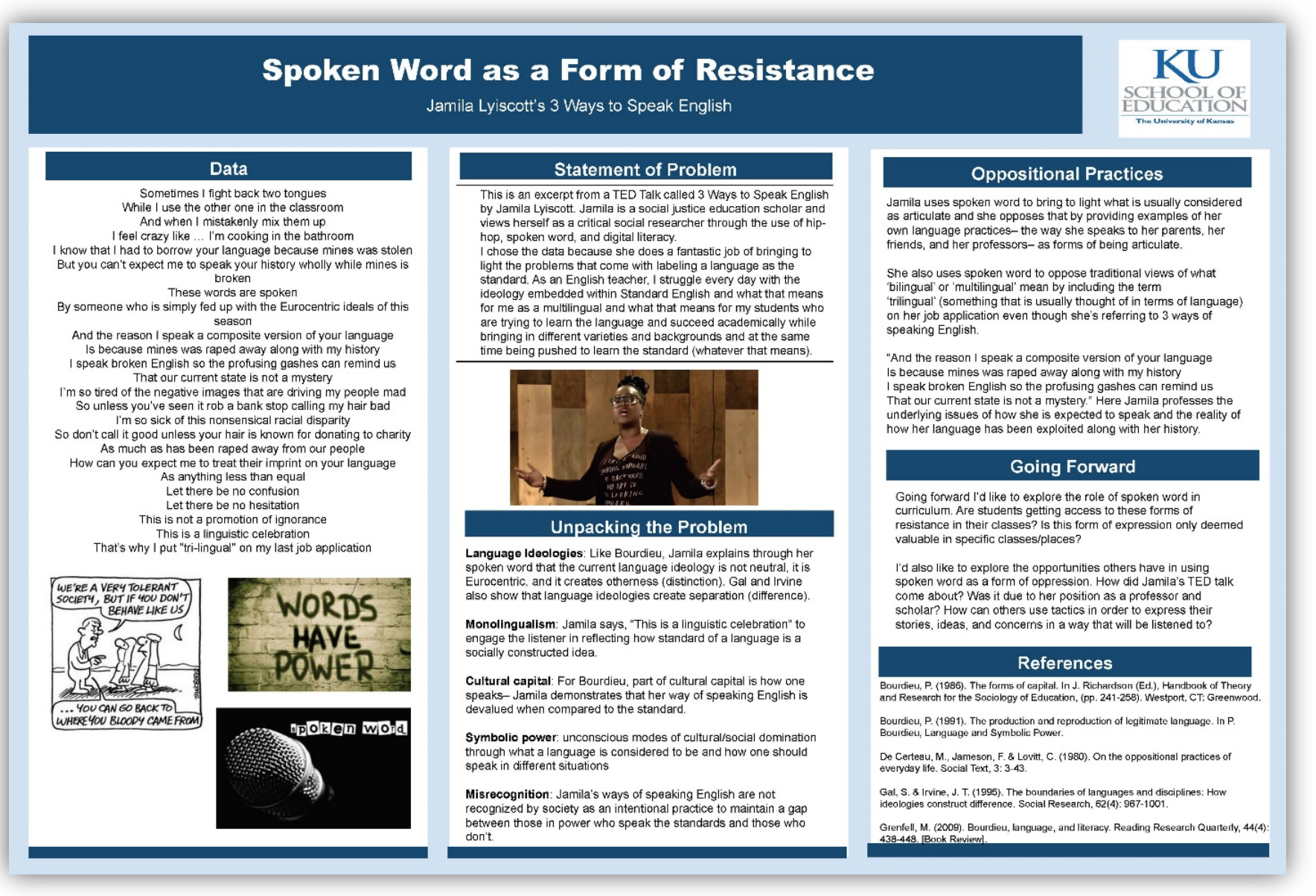

Fig. 3: Spoken word as a form of resistance

Furthermore, students are creating new ideas as they revoice old theoretical ideas and adapt them to new contexts and situations. In fact, Pennycook (2007) might suggest that students are (re)creating their own (different) understandings of old (same) ideas in applying them to novel sociopolitical and sociohistorical contexts. It is often possible to see the intertextual remnants of these old ideas in the key words that feature prominently in the headlines of students' conference posters_-"form of resistance," "habitus," and "capital". Revoicing occurs in dialogue with classmates with whom they share their ideas. In some cases, students work together to create their posters. This collaborative process allows students to engage in their own creative, innovative, and individualistic expression of knowledge and skill in ways that are co-constructive but also reflective of idiosyncratic style and creativity. 
Lastly, everyday creativity is exhibited in the assessment's grading rubric. Because students are dealing with theoretical concepts that do not have ready-made interpretations, it is important that students take some risks in their interpretation and application of theory to everyday data. To support risk taking and innovative expression, I designed a weighted rubric where the lowest grade students could receive for a completed poster was an $82 \%\left(" \mathrm{~B}-{ }^{\prime \prime}\right)$. The weighted rubric is an appropriate course of action for our graduate program where " $\mathrm{B}-$ " is the minimum passing grade for a course. More importantly, by removing the option of failure (short of not submitting a complete assignment), students were assured that they would not receive a failing grade for their attempts.

\section{Why Everyday Creativity Matters in Authentic Classroom Assessments}

Throughout this work, I have attempted to build a case for the presence of everyday creativity in authentic classroom assessments-perhaps not as a feature of all authentic classroom assessments, but as a fundamental potential of this category of assessment. Arguably, everyday creative potential lies in every authentic classroom assessment; it merely waits to be acknowledged, teased out, and presented to students as legitimate forms through which knowledge and skill can be expressed.

To authorize and legitimize the everyday creativity of authentic classroom assessments is to promote deeper student learning. Authentic classroom assessments foreground the real-world, complex, and contextual nature of applying knowledge and skills. In addition, these assessments demonstrate that creativity can include repetition, sameness, as well as difference (Pennycook, 2007); and they illustrate that innovation, novelty, and individuality of expression are natural products of higher-order thinking and more engaged dispositional stances (Darling-Hammond \& Snyder, 2000). Everyday creativity should be encouraged in the development and execution of assessments designed for preservice and inservice teachers. Allowing for such creativity can cultivate the intellectual and pedagogical risk taking our students need in their careers; and by providing these opportunities in our classrooms, authentic classroom assessments can serve as a shelter under which students can take risks and learn from mistakes.

Finally, to authorize and legitimize the everyday creativity of authentic classroom assessments is to unleash the everyday creativity that teachers possess. Creating, planning for, and implementing these authentic classroom assessments requires an educator to gain clarity about what needs to be taught, foregrounded, and announced to students in advance. The steps to make sure one has provided students with the information and support needed to successfully complete an assessment is a difficult and ongoing process of coming to know. It requires constant evaluation and reevaluation of how one teaches and prepares students to carry out tasks. This approach to assessment encourages everyday creativity, and it is the hallmark of the kind of teaching that can lead to deeper learning. 
The Everyday Creativity of Authentic Classroom Assessments

\section{References}

Ardalan, K. (2015). Using entertaining metaphors in the introduction of the case method in a case-based course. In L. Mang \& Y. Zhao (Eds.), Exploring learning \& teaching in higher education (pp. 69-96). Springer.

Bakhtin, M. M. (1984). Problems of Dostoevsky's poetics. University of Minnesota Press.

Beghetto, R. A. (2005). Does assessment kill student creativity? Educational Forum, 69, 254-263.

Bourdieu, P. (1977). Outline of a theory of practice. Cambridge University Press.

Carter, R. (2004). Language and creativity: The art of common talk. Routledge.

Catalano, T., \& Leonard, A. E. (2016). Moving people and minds: Dance as a vehicle of democratic education. Education, Citizenship and Social Justice, 11(1), 63-84.

Connelly, F. M., \& Clandinin, D. J. (1988). Teachers as curriculum planners. Teacher's College Press.

Darling-Hammond, L., \& Snyder, J. (2000). Authentic assessment of teaching in context. Teaching and Teacher Education, 16(5), 523-545.

Dez, M., Moon, J., \& Meyer, C. (1992). What do we want students to know? ... and other important questions. Educational Leadership, 49(8), 38-42.

Fahnestock, J. (1999). Rhetorical figures in science. Oxford University Press.

Fahnestock, J. (2003). Verbal and visual parallelism. Written Communication, 20(2), 123-152.

Frey, B. B., \& Schmitt, V. L. (2007). Coming to terms with classroom assessment. Journal of Advanced Academics, 18(3), 402-423.

Frey, B. B., Schmitt, V. L., \& Allen, J. P. (2012). Defining authentic classroom assessment. Practical Assessment, Research, and Evaluation, 17(2). http://pareonline.net/getvn.asp?v=17\&n=2

Garner, R. (2005). Humor, analogy, and metaphor: H.A.M. it up in teaching. Radical Pedagogy, 6(2). https://radicalpedagogy.icaap.org/content/issue6_2/garner.html

Glynn, S. (2007). The teaching-with-analogies model: Build conceptual bridges with mental models. Science and Children, 44(8), 52-55.

Goffman, E. (1974). Frame analysis. Harper \& Row.

Levien, R. (Writer, Director). (2009). Immersion: A short fiction film [Film]. Produced by R. Levien, K. Fox, \& Z. Poonen Levien. http://www.immersionfilm.com/

Newmann, F., Brandt, R. \& Wiggins, G. (1998). An exchange of views on semantics, psychometrics, and assessment reform: A close look at "authentic" assessments. Educational Researcher, 27(6), 19-22.

Newmann, F. M., Bryk, A. S., \& Nagaoka, J. K. (2001). Authentic intellectual work and standardized tests: Conflict or coexistence? Consortium on Chicago School Research.

Pennycook, A. (2007). "The rotation gets thick. The constraints get thin": Creativity, recontextualization, and difference. Applied Linguistics, 28(4), 579-596. 
Plucker, J. A., \& Beghetto, R. A. (2004). Why creativity is domain general, why it looks domain specific, and why the distinction doesn't matter. In R. J. Sternberg, E. L. Grigorenko, and J. L. Singer (Eds.), Creativity: From potential to realization (pp. 153-68). American Psychological Association.

Plucker, J. A., Beghetto, R. A., \& Dow, G. T. (2004). Why isn't creativity more important to educational psychologists? Potentials, pitfalls, and future directions in creativity research. Educational Psychologist, 39(2), 83-96.

Shin, J. K. (2017). Get up and sing! Get up and move!: Using songs and movement with young learners of English. English Teaching Forum, 55(2), 14-25.

Thomas, M. (2018a). Harry Potter and the border crossing analogy: An exploration of the instructional use of analogy in a TESOL methods course. Teacher Educator, 53(3), 277-292.

Thomas, M. (2018b). The girl who lived: Exploring the liminal spaces of self-study research with textual critical partners. In D. Garbett \& A. Ovens (Eds.), Pushing boundaries and crossing borders: Self-study as a means for knowing pedagogy (pp. 327-333). S-STEP.

Thomas, M. (2018c). Trauma, Harry Potter, and the demented world of academia. Journal of Educational Thought, 51(2), 184-203.

Thomas, M. (2019). "I solemnly swear that I am up to no good": Mapping my way through TESOL teacher education. Studying Teacher Education, 15(1), 82-92.

Thomas, M. (n.d.a). Instructional approaches for ESOL learners in the middle/secondary classroom. University of Kansas. https://ct.ku.edu/academics/courses.

Thomas, M. (n.d.b). Language, discourse, \& ideology. University of Kansas. https://ct.ku.edu/academics/courses.

Thomas, M., Russell, A., \& Warren, H. (2018). The good, the bad, and the ugly of pedagogy in Harry Potter: An inquiry into the personal practical knowledge of Remus Lupin, Rubeus Hagrid, \& Severus Snape. Clearing House: A Journal of Educational Strategies, Issues and Ideas, 91(4/5), 186-192.

Warner, C. (2009). Speaking from experience: Narrative schemas, deixis, and authenticity efforts in Verena Stefan's feminist confession Shedding. Language and Literature, 18(1), 7-23.

Wiggins, G. (1990). The case for authentic assessment. Practical Assessment, Research \& Evaluation, 2(2). http://PAREonline.net/getvn.asp? $v=2 \& n=2$.

Wiggins, G. (1993). Assessing student performance: Exploring the purpose and limits of testing. Jossey-Bass.

Wiggins, G. (1998). Ensuring authentic performance. In G. Wiggins (Ed.), Educative assessment: Designing assessments to inform and improve student performance (pp. 21-42). Jossey-Bass.

Wiggins, G. (2006). Healthier testing made easy: Tests don't just measure absorption of facts. They teach what we value. Edutopia, 49-51. https://www.edutopia.org/authentic-assessment-grant-wiggins. 


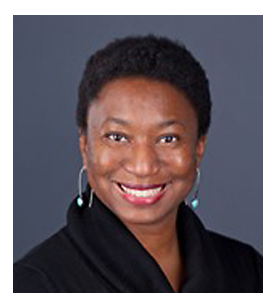

M'Balia Thomas is an Assistant Professor of TESOL at the University of Kansas. She holds a PhD from the University of Arizona in the Interdisciplinary Program in Second Language Acquisition and Teaching. As a TESOL Teacher Educator, she researches and writes on the everyday creativity of "nonnative" and "nonstandard" varieties of American English. 